\title{
"Ela veio da comunidade e para a comunidade": a criação de uma universidade no município do Rio Grande (RS)
}

\author{
Karin Christine Schwarzbold ${ }^{*}$
}

\section{Introdução}

O presente artigo tem por objetivo relatar o início do ensino superior no município do Rio Grande (RS), especificamente sob o olhar dos participantes do movimento estudantil secundarista. $\mathrm{O}$ movimento secundarista no município do Rio Grande teve seu início formalizado no II Congresso de Estudantes Secundaristas ocorrido nos dias 16 a 23 de agosto de 1953, junto ao Salão Nobre do Colégio São Francisco. Cria-se nesse momento a União dos Estudantes Secundaristas do Rio Grande (URES).

A URES tem forte atuação junto aos estudantes proporcionando atividades desportivas, culturais e atuando em causas sociais e políticas de interesse dos mesmos. Dentre as reinvindicaçóes está a implantação do ensino superior no município. Já em 1953, logo após a sua criação, tiveram a oportunidade de participarem de uma passeata solicitando a instalação da Faculdade de Engenharia Industrial, há algum tempo prometida, mas ainda não concretizada.

Para o presente artigo optou-se como metodologia o uso da Historia Oral. A História Oral teve seu início no século XX com o advento de tecnologias que tornaram possíveis o seu registro, tais como o gravador de áudio e vídeo. Isso só

* Doutoranda no Programa de Pós-Graduação em Educação pela Universidade Federal de Pelotas (UFPel) - Linha de Pesquisa: Filosofia e História da Educação. Arquivista pela Universidade Federal do Rio Grande (FURG). Desenvolve pesquisas na área da Educação, Memória e Patrimônio e Impressos com ênfase em Gestão de Acervos. E-mail: kgenealogia@gmail.com. 
foi possível graças a própria concretização das ciências humanas. Por ser recente, conforme Roger Chartier, os historiadores atuais, que se valem da metodologia da História Oral, "podem oferecer uma audição literal das palavras cuja história escrevem" (Chartier, 2014, p.7). Os demais "precisam escutar os mortos somente com os olhos e recobrar as velhas palavras em arquivos nos quais o vestígio escrito delas foi preservado" (Chartier, 2014, p.7).

A presente pesquisa pretende compreender o processo de criação da Universidade Federal do Rio Grande (FURG) e sua federalização sob a ótica do movimento de estudantes secundaristas "por meio da história local" (Thompson, 1992, p. 21), contribuindo dessa forma para uma nova perspectiva, um novo olhar, já que a História Oral "pode ser utilizada para alterar o enfoque da própria história e revelar novos campos de investigação" (Thompson, 1992, p. 22). Assim, "o desafio da história oral relaciona-se, em parte, com essa finalidade social essencial da história” (Thompson, 1992, p. 21).

No momento em que pretendemos compreender uma ação social, a utilização da História Oral possibilita esse feito através do uso de entrevistas. "O que fascina numa entrevista é a possibilidade de tornar a vivenciar as experiências do outro, a que se tem acesso sabendo compreender as expressóes de suas vivências" (Alberti, 2007, p. 18-19). A busca do pesquisador por um entrevistado se dá pela "busca de alguma informação e de algum conhecimento que aquele indivíduo detém, e que o próprio pesquisador - mesmo que muito bem informado e preparado não detém" (Alberti, 2007, p.23). Paul Thompson ressalta que "a utilização de entrevistas como fonte para historiadores profissionais vem de muito longe e é perfeitamente compatível com os padróes acadêmicos" (Thompson, 1992, p.22) e poderá proporcionar "um meio de descobrir documentos escritos e fotografias, que, de outro modo, não teriam sido localizados" (Thompson, 1992, p.25).

Com a História Oral, para o autor, "o processo de escrever história muda juntamente com o conteúdo... Essa mudança brota da natureza essencialmente criativa e cooperativa do método da história oral" (Thompson, 1992, p. 28-29), uma vez que é uma "história construída em torno das pessoas. Ela lança vida dentro da própria história e isso alarga o seu campo de ação... em suma, contribui para formar seres humanos mais completos" (Thompson, 1992, p. 44).

Para a execução dessa proposta foram realizadas três entrevistas, a saber: um entrevistado que vivenciou a criação da URES, um entrevistado que participou da URES no período da criação da atual FURG e um entrevistado que fez parte da direção logo após a criação da FURG. Optou-se pelo cuidado de não nomear os entrevistados no texto, atribuindo como identificação as letras A, B e C. Essa opção foi feita por mim, pesquisadora, já que os entrevistados estão cientes da participaçáo na pesquisa e também abriram mão de direitos autorais. A seguir apresento um breve resumo sobre o ensino superior no Brasil. 


\section{Ensino superior}

O ensino superior no Brasil foi se desenvolvendo de forma lenta desde 1808, juntamente com a chegada da família real portuguesa, até a proclamação da República em 1889, com a criação de faculdades isoladas, as quais possuíam como objetivo uma formação voltada aos profissionais que viriam a ocupar postos no Império. Surge a Escola de Cirurgia e Anatomia da Bahia. ${ }^{1}$ No mesmo ano também foram criadas as Faculdades de Anatomia e Cirurgia no Município do Rio de Janeiro - hoje, Faculdade de Medicina da Universidade Federal do Rio de Janeiro (UFRJ), e a Academia da Guarda Marinha - atual Escola Nacional de Engenharia da UFRJ. Anísio Teixeira (2005) lembra que éramos colônia de Portugal, que monopolizava as instituiçóes de ensino superior na metrópole e ainda acreditava que o país não tinha condiçóes de sustentar o ensino universitário.

Apenas através do Decreto $n^{\circ} 14.572,{ }^{2}$ de 23 de dezembro de 1920, é criada simbolicamente a Universidade do Rio de Janeiro, através da aglutinação das escolas de Direito, Medicina e Engenharia, com a administração comum de um reitor. O interessante dessa criação é que ela teve como motivo conferir o título de honoris causa ao Rei Alberto I da Bélgica.

Viero (2012) indica que somente em 1931, através do Decreto $n^{\circ} 19.851{ }^{3}$ é criado o Estatuto das Universidades, que tem por motivação a orientação e organização das instituições e discorre sobre os seus objetivos, como podemos ver no artigo $1^{\circ}$ : "o ensino universitário tem como finalidade: elevar o nível da cultura geral, estimular a investigação científica em quaisquer domínios dos conhecimentos humanos; habilitar ao exercício de atividades que requerem preparo técnico e científico superior [...]"; e, no artigo 5º relata que as universidades devem "congregar em unidade universitária pelo menos três dos seguintes institutos do ensino superior: Faculdade de Direito, Faculdade de Medicina, Escola de Engenharia e Faculdade de Educação, Ciências e Letras"; "dispor de capacidade didática, aí compreendidos professores, laboratórios e demais condiçóes necessárias ao ensino eficiente $[\ldots]$ ”.

1 A Escola de Cirurgia e Anatomia da Bahia foi criada a pedido de José Corrêa Picanço, em 1816 tem o nome alterado para Academia Médico-Cirúrgica da Bahia, no ano de 1832 chama-se Faculdade de Medicina da Bahia (1891). Com o passar dos anos, sofre alterações na nomenclatura: Faculdade de Medicina e Farmácia da Bahia (1901), Faculdade de Medicina da Universidade da Bahia (1946) e finalmente em 1965 torna-se Faculdade de Medicina da Universidade Federal da Bahia. Disponível em: <http://www.dichistoriasaude.coc.fiocruz.br/iah/pt/verbetes/escirba.htm>. Acesso em: 6 jun. 2020.

2 Disponível em: <https://www2.camara.leg.br/legin/fed/decret/1920-1929/decreto-14572-23-dezembro1920-508004-norma-pe.html>. Acesso em: 20 mai. 2020.

3 Disponível em: <https://www2.camara.leg.br/legin/fed/decret/1930-1939/decreto-19851-11-abril1931-505837-publicacaooriginal-1-pe.html>. Acesso em: 6 jun. 2020. 
Conforme Teixeira (2005), nos anos quarenta houve uma forte pressão para a expansão do ensino e o mesmo entrou em expansão indiscriminada (aumento e diversificação dos alunos); já na década de 1950, ocorreu uma busca pela modernização do ensino superior. Forma-se, na década de 1960, a rede de universidades federais, Santos e Cerqueira (2009, p. 4) informam que "entre 1946 e 1960, foram criadas 18 universidades públicas e dez particulares de maioria confessional católica e presbiteriana”.

Com o período da ditadura civil-militar há uma significativa mudança no ensino superior.

A reforma dos militares continha basicamente as seguintes mudanças: extinção da cátedra; fim da autonomia das faculdades; criação de institutos, faculdades e/ou escolas; introdução do sistema de créditos; ciclo básico antes da formação profissional; garantia da representação discente e docente; ingresso contínuo por carreiras e currículos mínimos fixados pelo MEC (não à flexibilização). (Santos; Cerqueira, 2009, p. 5).

Conhecer a formação das universidades, a participação da sociedade e, em especial nessa pesquisa, o envolvimento de estudantes secundaristas, contribui para a preservação da memória, uma vez que "pessoas e lugares são entrelaçados, pois o espaço, como lugar de coisa (ou das coisas), torna-se um sistema coletivo de imagens onde cada lugar possui uma história a ser contada" (Rezende, 2010, p. 102). Assim, apresento a seguir um breve histórico sobre o ensino superior no município do Rio Grande.

\section{Ensino superior no Rio Grande: das faculdades isoladas ao complexo universitário}

Na segunda metade do século XX, ${ }^{4}$ a realidade do Município do Rio Grande revelava a carência de escolas de nível superior. Com isso, há uma significativa evasão do número de estudantes com boas condiçôes econômicas, os quais se dirigiam a outros centros em busca de continuidade para seus estudos . Aqueles que não possuíam condiçóes financeiras acabavam náo dando continuidade aos seus estudos. Depois de concluídos os cursos, essa força jovem raramente

4 Informações baseadas no site da FURG, do Catálogo Geral. Infelizmente, o mais atual é o de 2015. Disponível em: <https://sistemas.furg.br/sistemas/paginaFURG/arquivos/menu/000000406.pdf>. Acesso em: 21 nov. 2018. 
retornava à cidade de origem a fim de participar do seu processo histórico, cultural e socioeconômico. A sensibilização dessa realidade, aliada ao propósito de modificá-la, resultou em um movimento cultural, cuja finalidade era a criação de uma Escola de Engenharia no Rio Grande, justificada pelo elevado número de profissionais na área sem qualificação superior específica e pelo parque industrial que aqui já existia. Mas, conforme Silveira (2012, p. 71), já em 1918, houve uma tentativa de implantação do ensino superior no município, com a criação da Faculdade de Farmácia, Odontologia e Obstetrícia do Rio Grande. Infelizmente, o número de inscritos foi pouco, ocasionando a não consecução da mesma.

Atendendo aos anseios da sociedade, em 24 de maio de 1955, pelo Decreto $\mathrm{n}^{\mathrm{o}} 37.378,5$ foi autorizado o funcionamento da Escola de Engenharia Industrial, reconhecida pelo Decreto $n^{\circ} 46.459,{ }^{6}$ de 18 de julho de 1959 , e federalizada pela Lei ${ }^{0} 3.893,{ }^{7}$ de 2 de maio de 1961, em seu oitavo artigo, como estabelecimento isolado. A partir de então outros cursos e faculdades passaram a existir no município. A Faculdade de Ciências Políticas e Econômicas surge pela Lei Municipal $\mathrm{n}^{\circ} 875,{ }^{8}$ de 22 de julho de 1955 , e foi autorizada a funcionar pelo Decreto $\mathrm{n}^{\circ} 43.563,{ }^{9}$ de 24 de abril de 1958.

Em 1959, ano do centenário de nascimento de Clóvis Beviláqua (autor do projeto do Código Civil Brasileiro, em 1899), foi iniciado um movimento visando à instalação de uma Escola de Direito em Rio Grande, a ser mantida financeiramente pela Mitra Diocesana de Pelotas. Contava com a colaboração de professores do município, da União Sul - Brasileira de Ensino (fornecendo as instalaçóes para o funcionamento) e da Bibliotheca Rio-Grandense, que disponibilizando o seu acervo à clientela. Visando o bem maior, a qualificação de pessoal no ensino superior, instituiçôes privadas do município, bem como da região, não mediram esforços em auxiliar o setor público para a consecução desse objetivo.

Os esforços conjugados garantiram que em 2 de fevereiro de 1960, pelo Decreto $\mathrm{n}^{\circ} 47.738,{ }^{10}$ fosse autorizado o funcionamento da instituição, que recebeu o nome de Faculdade de Direito Clóvis Beviláqua.

5 Disponível em: <https://www2.camara.leg.br/legin/fed/decret/1950-1959/decreto-37378-24-maio1955-333892-norma-pe.html>. Acesso em: 22 mai. 2020.

6 Disponível em: https://www2.camara.leg.br/legin/fed/decret/1950-1959/decreto-46459-18-julho1959-385794-publicacaooriginal-1-pe.html. Acesso em 6 jun. 2020.

7 Disponível em: <https://www2.camara.leg.br/legin/fed/lei/1960-1969/lei-3893-2-maio-1961-353670publicacaooriginal-1-pl.html>. Acesso em 6 jun. 2020.

8 Disponível em: <https://camara-municipal-de-rio-grande.jusbrasil.com.br/legislacao/535317/lei-87555>. Acesso em: 6 jun. 2020.

9 Disponível em: <https://www2.camara.leg.br/legin/fed/decret/1950-1959/decreto-43563-24-abril1958-382544-publicacaooriginal-1-pe.html>. Acesso em: 6 jun. 2020.

10 Disponível em: <https://www2.camara.leg.br/legin/fed/decret/1960-1969/decreto-47738-2-fevereiro1960-387273-norma-pe.html>. Acesso em: 22 mai. 2020. 
À medida que o tempo transcorria, novas expectativas surgiam, e com elas se ampliava a gama de possibilidades oferecidas aos jovens rio-grandinos. Ainda em 1960, tendo em vista o grande número de candidatos que desejavam outros cursos de nível superior, surge, em 19 de janeiro de 1961, através do Decreto ${ }^{\circ}$ $49.963,{ }^{11}$ a autorização para o funcionamento dos cursos de Filosofia e Pedagogia, para cujo funcionamento haviam sido cedidas salas da Escola Normal Santa Joana d'Arc. Essa escola, fundada em 1918, teve como objetivo atender a carência de formação da juventude feminina. ${ }^{12}$

Como um processo dinâmico, em 1964 era autorizado o funcionamento do Curso de Letras, com habilitação para inglês e francês; já em 1966, entrava em funcionamento o curso de Matemática; em 1967, instalavam-se os cursos de Ciências e Estudos Sociais. Nesse mesmo ano, na sessão de 4 de outubro, o Conselho Federal de Educação (CNE) reconheceu a Faculdade Católica de Filosofia de Rio Grande, ato oficializado pelo Pres. Arthur da Costa e Silva, através do Decreto ${ }^{\circ}{ }^{6} 61.617,{ }^{13}$ de 3 de novembro de 1967.

Até que, por fim, em 20 de agosto de 1969, foi assinado o Decreto-Lei ${ }^{\circ}$ $774,{ }^{14}$ pelo então Presidente da República Artur da Costa e Silva, autorizando o funcionamento da URG com a integração das faculdades existentes no município tornando-as administrativamente únicas em uma instituição de ensino superior. A seguir, uma breve contextualização do ensino secundário para compreensão da criação do movimento estudantil e sua luta pelo ensino superior no Rio Grande.

\section{O início do ensino secundário e do movimento estudantil secundarista no Rio Grande, RS}

O ensino secundário constitui-se na formação escolar que ocorre nos "três anos que sucedem o ensino básico e que precedem a formação universitária”

11 Disponível em: <https://www2.camara.leg.br/legin/fed/decret/1960-1969/decreto-49963-19janeiro-1961-389798-publicacaooriginal-1-pe.html>. Acesso em 6 jun. 2020.

12 O termo "juventude feminina" encontra-se na justificativa do Bispo da Diocese de Pelotas, Dom Francisco de Campos Barreto, com relação a criação de uma escola no município. Para maiores informações, sugiro a leitura do artigo "Colégio Santa Joanna d'Arc: uma narrativa histórica acerca da escola complementar e da primeira escola normal de Rio Grande/RS" de Rita de Cássia Grecco dos Santos, Francisco Furtado Gomes Riet Vargas e Elomar Tambara. Disponível em: <http://www.ucs.br/etc/conferencias/index. php/anpedsul/9anpedsul/paper/viewFile/2194/44>. Acesso em: 21 nov. 2018.

13 Disponível em: <https://www2.camara.leg.br/legin/fed/decret/1960-1969/decreto-61617-3novembro-1967-402786-publicacaooriginal-1-pe.html>. Acesso em: 6 jun. 2020.

14 Disponível em: <https://www2.camara.leg.br/legin/fed/declei/1960-1969/decreto-lei-774-20agosto-1969-374739-publicacaooriginal-1-pe.html>. Acesso em: 22 mai. 2020. 
(Ensino secundário, 2001). No período colonial, o ensino era de responsabilidade de ordens religiosas, em especial da Companhia de Jesus. Com uma concepção humanista, "visava à formação da jovem elite brasileira, que após a conclusão dos estudos secundários, iria cursar Teologia, Direito ou Medicina em Coimbra ou em Universidades da França" (Teixeira, 2017, p. 57).

Já no período imperial, em 15 de outubro de 1827, é promulgada a lei que "procurou criar um sistema de ensino para todos os cidadãos do Império" (Teixeira, 2017 , p. 58). A lei ao ser publicada, por si só, não garante a sua aplicação. Isso se deve, em especial, à falta de iniciativa e fomento do poder central com relação ao ensino público. Com a publicação de um ato adicional em 12 de agosto de 1834 fica "delegada às Assembleias Legislativas Provinciais o direito de legislar sobre a instrução primária e secundária, em seus respectivos domínios" (Teixeira, 2017, p. 59) cabendo ao governo central a responsabilidade pelo ensino superior e da capital.

Com a pouca atuação dos governos provinciais na oferta de vagas "o ensino privado acaba por encontrar um ambiente propício para se desenvolver" (Teixeira, 2017, p. 60). A elite necessita do ensino secundário "para que fosse possível o ingresso no ensino superior. Logo, a iniciativa privada se propaga visando preencher essa lacuna na educação, formação essa que os governos não conseguem respaldar" (Teixeira, 2017, p. 60). É importante esclarecer que o ensino secundário tinha a sua importância, mas, o mesmo não era uma etapa obrigatória para se inserir no ensino superior. Para tal, bastava lograr êxito nos exames preparatórios.

Com o fim da Primeira República, marcada pela Revolução de 30, há um aumento no investimento da produção industrial e no mercado interno, "com isso a demanda das indústrias exigia mão-de-obra especializada, consequentemente o investimento na educação era inevitável” (Teixeira, 2017, p. 7). Em 1930, com o início do governo Vargas, é criado o Ministério da Educação e Saúde Pública e há a sanção de decretos "com o objetivo de organizar o ensino secundário e as universidades brasileiras que nem existiam nessa época. Tratava-se da Reforma Francisco Campos" (Teixeira, 2017, p.8). Cabe ressaltar que até então o ensino secundário era regido pelos estados, não existindo uma política pública nacional apesar "da ideia de sistema nacional de ensino se fez presente em todos os projetos dede o final da década de 1860" (Saviani, 2011, p. 164).

No município do Rio Grande, desde o Império há uma preocupação por proporcionar algum tipo de instrução aos seus habitantes. Atualmente, com o nome de Bibliotheca Rio-Grandense, o então chamado na época Gabinete de Leitura teve importância vital para o andamento do ensino secundário no município, uma vez que era em suas dependências que as aulas ocorriam. Eram dadas disciplinas de forma isolada, por professores particulares que se valiam do 
ambiente para as ministraçóes. Na década de 1950, existiam no município quatro instituiçóes que ofertavam o ensino secundário, duas públicas (mistas) e duas particulares (uma masculina e outra feminina).

O colégio público Lemos Junior e o colégio particular (então apenas para meninos) São Francisco possuíam algum tipo de associativismo estudantil secundarista. Conforme o entrevistado A, um aluno de chegou do município vizinho de Pelotas (RS), seu pai veio transferido da rede férrea e foi estudar no Lemos Junior. Em Pelotas, estudava no Colégio Municipal Pelotense, instituição que tinha um forte movimento estudantil. Ele veio "com outras ideias, outra mentalidade, eles tinham grêmio" (Entrevistado A, 2019), com o pensamento de criar um movimento secundarista forte e homogêneo. Participou, juntamente com outros estudantes de um congresso em Bento Gonçalves (RS). A partir de então houve uma movimentação estudantil no município, culminando com a criação da União Rio-Grandina dos Estudantes Secundaristas (URES). Conforme o entrevistado, um dos focos da URES era a implantaçáo do ensino superior no município.

Discutiam os assuntos, um ensino mais gratuito, uma faculdade. Naquela época já se queria, porque só estudava fora quem tinha muito dinheiro. Quem era pobre não tinha como ir. Olha lá os que foram estudar em Pelotas, que se ia de trem ou de onibus, se atravessava a balsa. Era muito trabalho para se estudar em Pelotas. (Entrevistado A, 2019).

Formalizada em 1953, a URES já no seu início aproveita os desfiles cívicos para apresentar faixas reivindicando a criação da Faculdade de Engenharia Industrial, há algum tempo prometida, mas que ainda não saíra do papel.

Até então, os jovens que desejassem continuar os seus estudos precisavam mudar para outros municípios. A preocupação da sociedade local com a migração desses, que porventura ocasionaria algumas dificuldades nas relaçóes familiares, mas não apenas isso, a certeza de que não traria o progresso esperado ao município, causando sua estagnação já que, como afirmam Weiduschadt e Caetano (2016, p. 68), "a presença de uma instituição de ensino superior poderia aumentar as possibilidades de progresso no local”. Conforme Benevides (2006), os jovens se destacam como agentes sociais representantes de toda uma sociedade. Dessa forma, há uma reinvindicação da juventude e a sua participação ativa em um novo movimento cultural social: lutando e reivindicado acesso ao ensino superior. 


\section{"Ela veio da comunidade e para a comunidade": a luta dos estudantes secundaristas e da sociedade local pela implantação do ensino superior no município e a sua federalização}

Apesar do seu caráter elitista, o ensino superior é visto como necessário pela populaçáo rio-grandina, que anseia pelo mesmo no município e, especialmente, para os munícipes. Como afirma Vanessa Barrozo Teixeira, sobre o ensino no município, "era crescente a oferta e a procura por qualificação na própria cidade do Rio Grande, visando os indivíduos que permaneciam na cidade, em cursos ali existentes" (Teixeira, 2013. p. 84).

Havia entre os munícipes "a consciência quanto à perda do potencial humano que a cidade sofria” (Novo, 2004, p. 78), e que moradores não logravam êxito no município e precisavam partir para outras localidades. Tal fato era economicamente custoso para alguns, todavia não apenas isso, a dúvida que pairava era se esses acadêmicos retornariam para exercer suas profissóes no município.

Após a conquista de algumas faculdades no município, a luta do movimento estudantil secundarista não se encerra. Diante de uma oferta limitada de cursos inicia-se o trabalho pela conquista de uma universidade.

Por que na verdade, numa época que nós tínhamos faculdades isoladas, os estudantes secundários tinham dificuldades, aqueles que não queriam aqueles cursos que já estavam instalados, eles pensavam em ter uma universidade. E eu peguei bem esta fase porque eu comecei o meu segundo grau, na época científico, em 67, que foram os anos que antecederam bem diretamente o 69, que foi o da criação da universidade. Então, esse movimento foi um movimento que tomou bastante corpo. Além das forças vivas da cidade se preocupar com isso, os estudantes secundários que estavam prestes a fazer o vestibular e entrar em uma universidade, em cursos que aqui não havia, começaram a lutar pela criação de uma universidade. (Entrevistado B, 2019).

Através de várias reuniôes em Brasília, com diversos membros da sociedade local e em especial com a URES, em 1969 é criada a Universidade do Rio Grande.

Então na verdade foi um movimento muito, vamos dizer assim, comunitário. Porque não foram só os estudantes secundários, foram a Câmara do Comercio e Industria, a Fundação Cidade do Rio Grande, que teve uma influência tremenda nisso, porque era a criadora do primeiro curso superior 
na cidade, o de Engenharia. Esse movimento teve nos estudantes secundários uma força bem grande. Na época havia um movimento estudantil organizado que foram a Brasília. As outras entidades também estavam participando, etc., mas esse deslocamento que estou me referindo foi diretamente do movimento estudantil. Nós fomos a Brasília, tivemos entrevista na época com o chefe da Casa Civil, que era rio-grandino, o ministro Golbery do Couto e Silva, e isso foi tấo forte que o ministro da educação veio a Rio Grande. O Tarso Dutra. Ele veio a Rio Grande, depois de ter recebido o pessoal lá ele veio aqui e fez parte de uma reunião que se lutava por uma universidade que tinha um nome diferente, a universidade que se lutava na época era a Universidade do Litoral. E isso tomou corpo, tomou corpo a tal ponto que num jogo de futebol...Quem estava narrando a partida era o Paulo Correa, da Rádio Minuano, e ele foi quem deu em primeira mão, inclusive o Paulo Correia veio a ser depois meu colega de turma no Direito, ele deu em primeira mão a notícia de que tinha sido assinado o decreto de criação da universidade e o estádio aplaudiu, numa manifestação assim, numa comprovação digamos de que a comunidade esperava isso. E a FURG sempre teve esse viés, esse viés comunitário. Ela veio da comunidade e para a comunidade. Não foi ninguém que fez pousar uma universidade aqui. (Entrevistado B, 2019).

Foram várias idas e vindas a Brasília, reuniôes e discussōes sobre a criação de uma universidade no interior do Rio Grande do Sul porque, até entáo, o Estado Brasileiro tinha por padrão possuir faculdades isoladas em alguns municípios e nas capitais uma universidade.

Num momento em que os estados brasileiros tinham no máximo uma ou duas universidades federais, a maior parte nas capitais, eram poucos os estados que tinham mais de uma e nós já tínhamos duas, antes das nossas duas de Pelotas e Rio Grande. Que eram Santa Maria e Porto Alegre. Então como que um estado vai ter quatro universidades? (Entrevistado B, 2019).

Apesar de alguma relutância inicial por parte do governo federal, enfim, em 1969 é criada a Universidade do Rio Grande, através da aglutinação de faculdades já existentes no Município.

A universidade aqui foi criada através de um decreto do Presidente Artur da Costa Silva, em agosto de 69. Aí ela congregou várias faculdades. De Direito e Filosofia, que funcionavam, a do Direito no Colégio São Francisco e a de Filosofia no Santa Joana d'Arc, que hoje é o Bom Jesus. Então, pertenciam 
a Mitra Diocesana de Pelotas e eles entregaram para a novel Fundação Universidade do Rio Grande. A prefeitura tinha a Faculdade de Economia que funcionava ali na Luiz Lorea, que hoje é um prédio da universidade. A Fundação Cidade do Rio Grande tinha conseguido um Curso de Medicina. E a Faculdade Federal de Engenharia Industrial foi 'desfederalizada', e isso deu um problema na época porque os professores eram federais, e absorvidos pela universidade. Diversos cursos, né? E coube a unificação e a estruturação a um grande reitor, o professor Eurípedes Falcão Vieira, criação de novos cursos, como de Oceanologia. E o prof. Eurípedes conseguiu com o prefeito a doação da área onde hoje é o Campus Carreiros. (Entrevistado C, 2019).

Graças a todo o esforço da comunidade local, empresários, políticos, e aos próprios estudantes, a Universidade do Rio Grande foi criada tendo a Fundação Cidade do Rio Grande como sua mantenedora. Com isso, surge uma nova batalha para o movimento estudantil, dessa vez integrando a URES com o Diretório Central dos Estudantes (DCE): a gratuidade do ensino superior através da federalização da instituição.

A partir da década de 70, eu fui presidente da URES, em 71 e 72 , e quando fui para a universidade, fui para o DCE, e o coronel Cid, por todo o trabalho que eu tinha feito, me convidou para ser candidato a vereador. E eu fui e me elegi com mandato gratuito, de 73 a 75 . As reunióes eram a noite para que os vereadores pudessem trabalhar. E aí com o meu trabalho, na câmara e no DCE, nós começamos a nos mobilizar e trabalhar em outro sentido. Sendo fundação, os alunos pagavam mensalidade. Isso representava $8 \%$ do orçamento da universidade. Aí começamos a realizar um trabalho junto ao governo federal para que o MEC cobrisse esses $8 \%$ e os alunos passassem a náo pagar mais nada. Era pouco o que os alunos pagavam, mas pagavam. (Entrevistado C, 2019).

Apesar de ter sido mencionado pelo Entrevistado C que o valor pago para cursar a universidade, na opinião dele, era pouco, com certeza para muitos discentes poderia representar uma parcela substancial de sua renda pessoal e até mesmo familiar. Dessa forma, a luta pela federalização se justifica como uma oportunidade de trabalhadores poderem ter ascensão em suas carreiras e até mesmo acesso a uma nova profissão, bem como para os jovens recém-egressos do ensino secundário.

Nesse interim, mudou o comando da reitoria, tivemos o apoio do prof. Eurípedes. E passamos a ter o apoio do professor Fernando Lopes Pedone. 
E nós pedimos na época para o prof. Vidal Áureo Mendonça, que era o subreitor administrativo, que nos fizesse um trabalho orçamentário para levarmos ao MEC. Eu, como vereador e secretário geral do DCE, juntamente com o Carlos Alberto Monteiro Badejo e o Paulo Renato de Moura Cuchiara, que era o presidente do DCE, fomos a Brasília, levamos esse trabalho, sempre acompanhados pelo deputado Nelson Marchezan, e na primeira tentativa nos reunimos com o ministro que chamou os técnicos da época e teve alguma resistência. Mas nós não desistimos, nós continuamos trabalhando e o Marchezan cobrando. Aí muda o governo. Assume o presidente Ernesto Geisel e ele leva para ministro da Casa Civil, um rio-grandino, o ministro Golbery do Couto e Silva. Aí, nós voltamos a Brasília. O ministro da Educação era o ministro Nei Braga. Via Marchezan, nós tivemos uma audiência com o ministro Golbery, nos apresentamos, fomos muito bem recebidos, a dona Lurdinha era uma senhora já de idade, secretária dele, e o ministro Golbery deu ordem que quando os meninos de Rio Grande chegassem, não precisavam nem marcar audiência, que as portas estavam abertas, e isso sempre aconteceu, seguidamente. Aí nós contamos a odisseia que nós estávamos querendo que se resolvesse, da nossa luta, aí o ministro Golbery ligou para o ministro da educação e nisso fomos recebidos. E ai o ministro Nei Braga, chamou os técnicos do MEC, levaram todo o trabalho, com o nariz torcido, de má vontade, porque a dificuldade, falta de dinheiro, como sempre. O ministro Nei Braga disse o que consideram umas palavras mágicas, esses meninos são lá de Rio Grande e quem tá pedindo isso é o chefe. E o chefe era o Golbery, aí a gente viu que ele mandava. Aí as coisas começaram a acontecer. (Entrevistado C, 2019).

Após cinco, seis anos de muita conversa, reuniōes, idas e vindas a Brasília, enfim, a Universidade do Rio Grande, que tinha a sua mantenedora a Fundaçáo Cidade do Rio Grande, se torna federalizada no governo do entáo Presidente da República General João Baptista Figueiredo.

Apesar de toda a movimentação estudantil e da sociedade manterem uma postura neutra com relação a partidos políticos o Entrevistado C desabafa: "e esse trabalho que eu, o Badejo, que já faleceu e o Cuchiara, que esse trabalho realizado pelos alunos foi apagado do site pelas últimas administrações, que tem viés político, não concordo com isso, porque é história”. (Entrevistado C, 2019). 


\section{Considerações finais}

A criação da atual FURG, em agosto de 1969, foi uma consequência do movimento cultural e social local, engajando os trabalhos de políticos, empresários, militares e, também, do movimento estudantil secundarista.

Talvez possa parecer para alguns leitores muita pretensáo da minha parte, mas através dessa pesquisa, cujo objetivo foi relatar o início do ensino superior no município do Rio Grande, especificamente sob o olhar dos participantes do movimento estudantil secundarista, posso afirmar que a URES teve um papel de destaque junto a sociedade local para o início do ensino superior no Rio Grande, a criaçẫo da universidade e, por fim, a sua federalização. Infelizmente essa parte da história teve o seu conteúdo "apagado" de fontes oficias que relatam o início do ensino superior no município. Dessa forma, esse artigo rememora essa atuação através de relatos de pessoas envolvidas no ato e auxilia na preservação da memória local.

\section{Referências}

ALBERTI, Verena. Ouvir Contar: textos em história oral. Rio de Janeiro: Editora FGV, 2007.

BENEVIDES, Silvio César Oliveira. Na contramão do poder: juventude e movimento estudantil. São Paulo: Annablume, 2006.

CHARTIER, Roger. A mão do autor a mente do editor. Tradução George Schlesinger. São Paulo: Editora UNESP, 2014.

ENSINO SECUNDÁRIO. In: HOUAISS, Antônio. Dicionário Eletrônico Houaiss de Lingua Portuguesa. Rio de Janeiro: Objetiva, 2001. 1 CD-ROM. Versão 1.0.5

NOVO, Luciana Florentino. Importância da FURG no desenvolvimento econômicosocial do município do Rio Grande. Dissertação (Mestrado em Administração) - UFSC, Florianópolis, SC, 2004.

REZENDE, Maiquel Gonçalves de. Silêncio e esquecimento: Henrique Carlos de Morais e a construção de um agente de preservaçáo do patrimônio em Pelotas (1933-1986). Dissertação (Mestrado em Memória Social e Patrimônio Cultural) - UFPel, Pelotas, RS, 2010. 
SANTOS, Adilson Pereira dos; CERQUEIRA, Eustáquio Amazonas de. Ensino Superior: trajetórias históricas e políticas recentes. In: COLÓQUIO NACIONAL SOBRE A GESTÃO UNIVERSITÁRIA NA AMÉRICA DO SUL, 9, 2009, Florianópolis. Anais... Florianópolis: UNPEAU: 2009. Disponível em: <https://repositorio.ufsc.br/xmlui/ bitstream/handle/123456789/35836/Ensino\%20Superior\%20trajetoria\%20historica\%20 e\%20politicas\%20recentes.pdf?sequence=1\&isAllowed=y>. Acesso em: 6 jun. 2020.

SAVIANI, Dermeval. História das ideias pedagógicas no Brasil. 3. ed. rev. Campinas: Autores Associados, 2011.

SILVEIRA, Josiane Alves da. Faculdade Católica de Filosofia de Rio Grande: os primeiros anos da formaçáo docente no ensino superior da cidade (1960-1969). Tese (Doutorado em Educação) - UFPel. Pelotas, RS, 2012.

TEIXEIRA, Anísio. Ensino Superior no Brasil: análise e interpretação de sua evolução até 1969. 2. ed. Rio de Janeiro: UFRJ, 2005.

TEIXEIRA, Vanessa Barrozo. A Instrução da Mocidade Rio-grandina: $\mathrm{O}$ ensino secundário na sociedade do Rio Grande/RS (1850-1889). Tese (Doutorado) Programa de PósGraduação em Educação, Faculdade de Educação, UFPel, 2017.

THOMPSON, Paul. A voz do passado: história oral. Tradução Lólio Lourenço de Oliveira. Rio de Janeiro: Paz e terra, 1992.

VIERO, Tatiane Vedoin. Programa de extensão universitária: perspectivas emergentes na educação em ciências. Dissertação (Mestrado em Educação em Ciências: Química da Vida e Saúde) - FURG, Rio Grande, RS, 2012.

WEIDUSCHADT, Patrícia; CAETANO, Ademir Cavalheiro. Faculdade de Ciências Políticas e Econômicas, RS: ensino superior e alteraçóes do cotidiano da cidade do Rio Grande. Revista Brasileira de Ensino Superior, Passo Fundo, v. 2, n. 3, p. 67-78, jul./set. 2016. Disponível em: $<$ https://seer.imed.edu.br/index.php/REBES/article/view/1346>. Acesso em: 10 jun. 2020.

\section{Fontes orais}

ANJOS, Wlady Aguiar dos (Entrevistado A). [ago. 2019]. Entrevistador: Karin Christine Schwarzbold. Rio Grande, RS, 22 ago. 2019.

GONÇALVES, Péricles Antonio Fernandes (Entrevistado B). [jul. 2019]. Entrevistador: Karin Christine Schwarzbold. Rio Grande, RS, 15 jul. 2019.

LEMPEK, Renato Tubino (Entrevistado C). [jul. 2019]. Entrevistador: Karin Christine Schwarzbold. Rio Grande, RS, 31 jul. 2019. 
Resumo: $\mathrm{O}$ artigo objetiva relatar o início do ensino superior no município do Rio Grande (RS), especificamente sob o olhar dos participantes do movimento estudantil secundarista. O movimento secundarista no município do Rio Grande teve seu início formalizado no II Congresso de Estudantes Secundaristas, ocorrido entre os dias 16 e 23 de agosto de 1953, junto ao Salão Nobre do Colégio São Francisco. Para a execução dessa proposta, foram realizadas três entrevistas. A saber: um entrevistado que vivenciou a criação da União dos Estudantes Secundaristas do Rio Grande (URES), um entrevistado que participou da URES no período da criação da atual Universidade Federal do Rio Grande (FURG) e um entrevistado que fez parte da direção logo após a criação da FURG. Após a conquista de algumas faculdades no município, a luta do movimento estudantil secundarista não se encerrou. Diante de uma oferta limitada de cursos, inicia-se o trabalho pela conquista de uma universidade. Então, após a criação da Universidade do Rio Grande, em 1969, o trabalho não se dá por encerrado, iniciando-se a luta do movimento estudantil secundarista pela federalização da instituição e, assim, a garantia de sua gratuidade. Dessa forma, este artigo rememora essa atuação através de relatos de pessoas envolvidas nos atos e auxilia na preservaçáo da memória local.

Palavras-chave: Ensino Superior. Movimento Estudantil Secundarista. FURG. Rio Grande.

\title{
"She came from the community and for the community": the creation of a university in the municipality of Rio Grande (RS)
}

\begin{abstract}
This article aims to narrate the beginning of higher education at the city of Rio Grande (RS), more specifically, under the view of high school student's movement at that time. The high school student's movement in Rio Grande officially begun at the II High School Student's Congress that took place at São Francisco School Noble Hall, between august 16 and 23, 1953. To develop this study, three interviews were conducted: an interviewee who experienced the creation of Union of High School Students (URES), an interviewee who was a member of URES by the time when the Universidade Federal do Rio Grande (FURG) was created and an interviewee who was a part of the management soon after the establishment of FURG. After bringing some colleges to the city, the struggle of the high school student's movement does not end. Due to a limited offer of courses, start the work on conquer a university. Then, after the establishment of the Universidade do Rio Grande, in 1969, the work is still not finished, now begins the high school student's movement struggle the institution federalization, thus, ensuring its gratuity. Therefore, this work recollects the high school student's movement through narratives from people involved in the acts and helps to preserving the local memory.
\end{abstract}

Keywords: Higher education. High school student's movement. FURG. Rio Grande.

Recebido em 25/03/20

Aprovado em 25/05/20 